\title{
Dynamic Response of AP1000 Nuclear Island Due to Safe Shutdown Earthquake Loading
}

\author{
Buntara S. Gan ${ }^{1, *}$, Dinh Kien Nguyen ${ }^{2}$, and Ay Lie $\mathrm{Han}^{3}$ \\ ${ }^{1}$ Department of Architecture, College of Engineering, Nihon University, Koriyama, Japan \\ ${ }^{2}$ Institute of Mechanics, VAST, 18 Hoang Quoc Viet, Hanoi, Vietnam \\ ${ }^{3}$ Department of Civil Engineering, Diponegoro University, Semarang, Indonesia
}

\begin{abstract}
AP1000 is a standard nuclear power plant developed by Westinghouse and its partners by using an advanced passive safety feature. Among the five principle building structures, namely the nuclear island, turbine building, annex building, diesel generator building and radwaste building, the safety of the nuclear island building is the most concerned. This paper investigates the dynamic response of the nuclear island building of the AP1000 plant subjected to safe shutdown earthquake loadings. A finite element model for the building, which is assumed to be built in a hard-rock base, is developed and its dynamic response is computed with the aid of the commercial finite element package ANSYS. The dynamic characteristics, including the natural frequencies, the vibration modes, and the time histories for displacements, velocities, and accelerations of the building are obtained for two typical safe shutdown earthquakes, El Centro and Kobe earthquakes. The dynamic behavior of the building due to the earthquakes and its safety is examined and highlighted.
\end{abstract}

\section{Introduction}

The safety of nuclear power plants in earthquakes is the most concern for engineers and researchers in designing a new plant as well as in evaluating the existing plants [1]. Due to the complexity of the nuclear structure and the seismic loading, it is very difficult to carry out a site test. The dynamic finite element analysis is a preferable tool to predict the dynamic response of the nuclear power structures under the action of seismic loading. Investigations on the dynamic behavior of nuclear power plant by using both the commercial finite element packages and self-developed codes have been extensively reported in the literature.

Tunon-Sanjur et al. [2] considered the soil-structure interaction in the development of the stick and shell finite element models of AP1000 nuclear island for dynamic investigation of the island under seismic loading. Manjuprasal et al. [3] developed a 20node isoparametric solid finite element for investigating the nonlinear behavior of reinforced concrete containment shell of nuclear plants under seismic loading. It has been shown by the authors that the material nonlinearity which considered in their work has a significant influence on the dynamic response of the structure and the dynamic

*Corresponding author: buntara@arch.ce.nihon-u.ac.jp 
displacement increases considerably when the effect of material nonlinearity is taken into account. In [4], Nakamura proposed the methods to transform the frequency-dependent soil impedance to the time domain for predicting the seismic behavior of a deeply embedded nuclear power building. The author then employed the finite element method in combination with the direct integration Newmark method to obtain the vibration characteristics of the building. Continue his work in [4], Nakamura and his co-workers [5] carried out a study on the ultimate seismic response and fragility assessment of a nuclear power building by developing a nonlinear three-dimensional finite element model. Perotti et al. [6] proposed a numerical procedure for evaluating fragility of isolated nuclear buildings under seismic loading. The procedure makes use of the response surface methodology to model the influence of random variables on the dynamic response which can be able to apply to the design of the nuclear power plant reactor. Zhao and Chen [7] used the finite element method to study the dynamic behavior of a nuclear power reinforced concrete containment with or without damping rubber bearing isolators under threedirectional seismic loading. Chen et al. [8] employed the ANSYS software in to investigate the dynamic response of isolated and non-isolated nuclear island building under seismic loading. The numerical investigation carried out by the authors showed that the behavior of the isolated structure is very different from that of the non-isolated one, and the natural frequencies and dynamic displacements of the isolated structure are significantly lower than that of its counterpart. A three-dimensional finite element model of the reinforced concrete containment building was developed by Zhai et al. [9] for studying the dynamic behavior of the building under the mainshock-aftershock earthquake sequences. Politopouos et al. [10] modeled the soil domain under the nuclear power plant by the finite elements and Lysmer radiation boundaries for investigation of the effect of foundation embedment on the floor response spectra of the plant. It has been shown by the authors that the base rocking excitation induced by soil-structure interaction, may amplify the non-isolated modes' response. A 3D nonlinear inelastic finite element model was developed and incorporated into the finite element software ABAQUS by Sener et al. [11] for investigating studying the seismic behavior of a pressurized water reactor containment internal structure. Recently, $\mathrm{Xu}$ et al. [12] took the effect of water level in water tank into their study of the dynamic response of the AP1000 shield building under seismic loading.

The AP1000 is a standard nuclear power plant developed by Westinghouse and its partners by using an advanced passive safety feature. The system has been approved by some countries and under consideration by the others. The safety system of theAP1000 plant includes the facilities inside and outside of the containment vessel [13]. Understanding the dynamic behavior of AP1000 buildings and their facilities in earthquakes is very important, especially for a country with many earthquakes likes Japan. In this paper, as a first attempt, the dynamic response of AP1000 nuclear island building due to safe shutdown earthquake loading is investigated. With the help of the commercial software ANSYS, a three-dimensional finite element model for the building is developed, and its dynamic response is computed. The dynamic characteristics, including the natural frequencies, time histories for displacements, accelerations and von Mises stresses are obtained for the building under the safe shutdown of 19944 El Centro and 1955 Kobe earthquakes. The dynamic behavior of the building in the earthquakes and its safety are examined and highlighted.

\section{Seismic finite element analysis}

In the context of finite element method, the equations of motion for dynamic analysis of a structure under seismic loading is of the form [14] 


$$
\mathbf{M} \ddot{\mathbf{D}}+\mathbf{C D}+\mathbf{K D}=-\mathbf{M I} \ddot{\mathbf{D}}_{g}(t)
$$

where $\mathbf{M}, \mathbf{C}, \mathbf{K}$ are, respectively, the mass, damping and stiffness matrices of the structure; $\mathbf{D}$ is the vector of unknown relative nodal displacements, $\dot{\mathbf{D}}=\partial \mathbf{D} / \partial t, \ddot{\mathbf{D}}=\partial^{2} \mathbf{D} / \partial t^{2}$ are the relative nodal velocities and nodal; $\ddot{\mathbf{D}}_{g}$ is the vector of ground motion which relates to the vectors of absolute and relative nodal accelerations by

$$
\ddot{\mathbf{D}}_{g}(t)=\ddot{\mathbf{D}}_{a}-\ddot{\mathbf{D}}
$$

with $\ddot{\mathbf{D}}_{a}$ denotes the vector of absolute nodal accelerations. In Eq. (1), I is the influence coefficient vector, having 1 for elements corresponding to degrees of freedom in the direction of the applied ground motion and zero for the other degrees of freedom. The proportional damping is adopted herein. In this regard, the damping matrix $\mathbf{C}$ is formed as a linear combination of the stiffness and mass matrices as

$$
\mathbf{C}=\alpha \mathbf{K}+\beta \mathbf{M}
$$

where $\alpha$ and $\beta$ are, the stiffness and mass proportional damping coefficients, respectively. These damping coefficients can be calculated from the critical damping ratio and the structural natural frequencies as

$$
\alpha=2 \xi \frac{\omega_{1} \omega_{2}}{\omega_{1}+\omega_{2}}, \quad \beta=\frac{2 \xi}{\omega_{1}+\omega_{2}}
$$

where $\xi$ is the damping ratio, depending on the structural material, and in the present work $\xi=5 \%$ is assumed for both the concrete and steel; $\omega_{1}$ and $\omega_{2}$ are natural frequencies of the structure, which are necessary to choose to bound the design spectrum. $\omega_{1}$ is normally selected as the fundamental frequency, and a value of $30 \mathrm{~Hz}$ is chosen for the frequency $\omega_{2}$ because the spectral contents of seismic design are insignificant above this frequency [15].

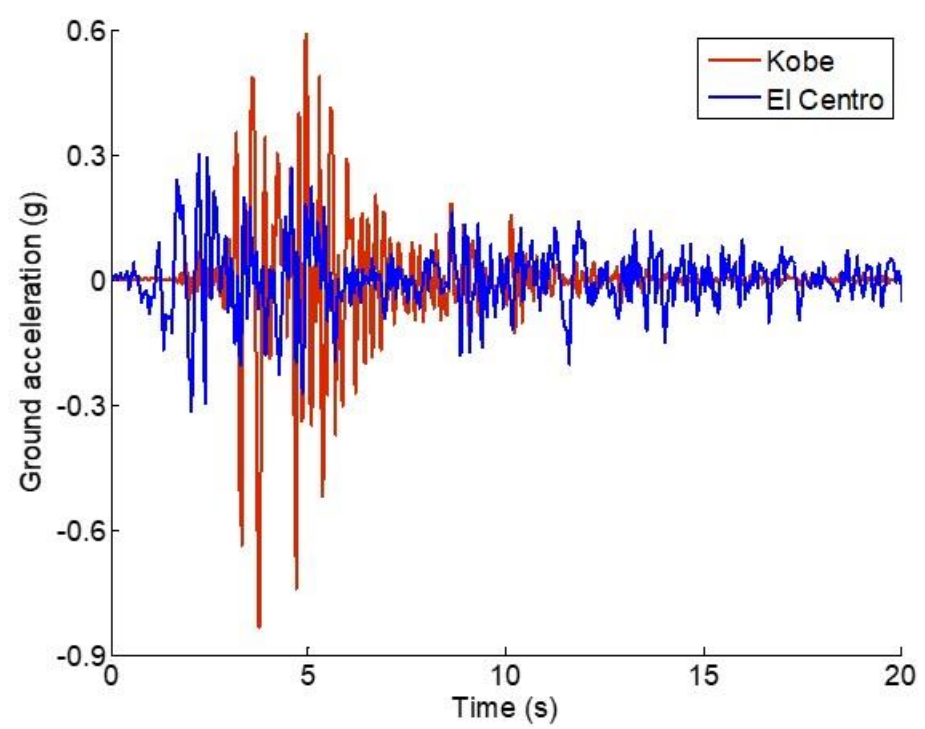

Fig. 1. N-S ATHs of Kobe and El Centro earthquakes.

In order to evaluate the dynamic behavior of the nuclear island building under the safe shutdown earthquakes, the input Acceleration Time Histories (ATH) of the earthquakes are 
applied at the base of the building. Fig. 1 shows the N-S ATHs of the 1944 El Centro and 1955 Kobe earthquakes, which are plotted from the seismic data of these earthquakes. As seen from the figure, the peak ground motion (PGA) of the Kobe earthquake is more than twice times higher than that of the El Centro earthquake, but the ground acceleration of the Kobe earthquake decays rapidly after 10 seconds.

\section{Finite element model}

Among the five buildings of the AP1000 nuclear power plant, the nuclear island building contains the steel containment vessel and other important equipment. Therefore the safety of this building is the most important. Fig. 2 shows an imagination of the AP1000 nuclear island building.

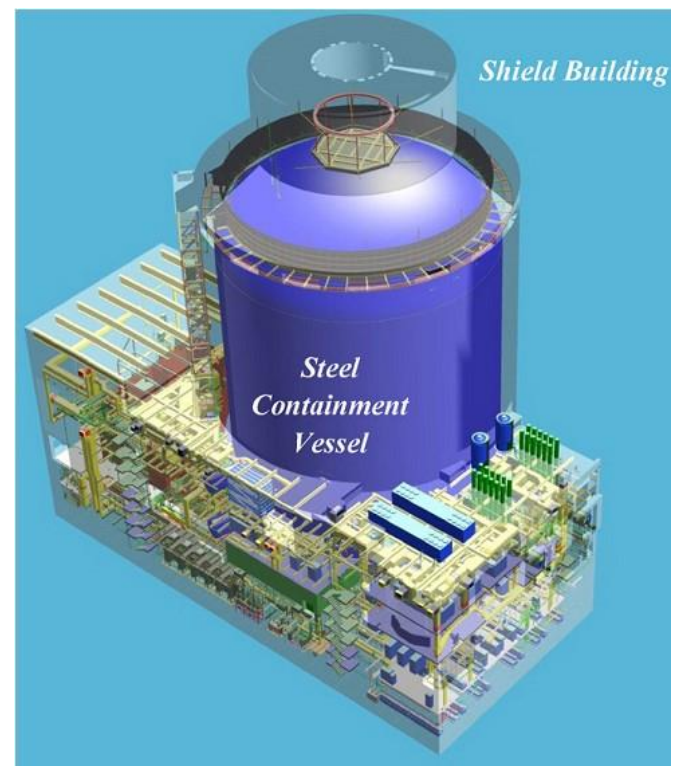

Fig. 2. Nuclear island building of the AP1000 [2].

Investigation on the dynamic behavior of the nuclear power plants, as discussed in the introduction section, has been carried out intensively. Various methods for safety evaluation necessary to carry out pre-earthquake and after-earthquake are discussed in [16]. Regarding the AP1000 nuclear island considered herein, due to the complexity of the structure, it is difficult to consider many factors such as the soil-structure interaction, nonlinearity of the material, water levels in the tank and air intakes at the same time. In the present work, the nuclear island building is considered to be built on a hard rock base, and the equipment inside the building is not modeled separately. With the help of the "Geometry" library in ANSYS R15.0 [17], a 3D finite element model for the AP1000 nuclear island building is created and shown in Fig. 3. Both the concrete structures and steel containment vessel are incorporated in the model. The model consists of shell and brick elements, in which the shell elements are used to model the steel containment vessel and the shield building, whereas the remaining parts are modeled by the brick elements. The interface between the upper part of the building and the base mat as well as between the walls of the building and the upper base mat are modeled by the share node option of ANSYS. The convergence of the mesh has been carried out in order to find out an acceptable mesh. Finally, a mesh with a total number of 88349 elements, in which 2192 
elements are shared node elements, is decided to employ in the analysis. Table 1 lists the geometric and material data of the nuclear island building which will be used in computation the dynamic response.
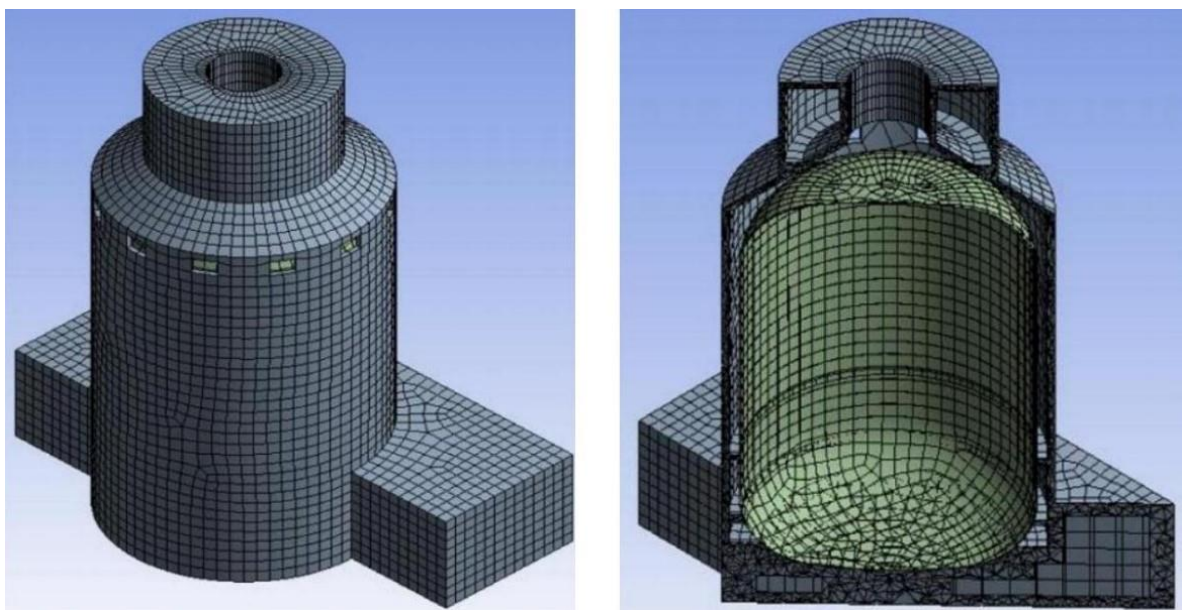

Fig. 3. Finite element model of AP1000 nuclear island building.

Table 1. Geometry and material data of AP1000 nuclear island used in the analysis [8].

\begin{tabular}{|l|c|c|c|}
\hline \multicolumn{1}{|c|}{ Item } & Concrete & Steel & Size \\
\hline Density $\left(\mathrm{kg} / \mathrm{m}^{3}\right)$ & 2300 & 7800 & \\
\hline Young's modulus (MPa) & $3.35 \times 10^{4}$ & $2.06 \times 10^{5}$ & \\
\hline Poisson's ratio & 0.2 & 0.3 & \\
\hline Length of nuclear island (m) & & & 77.42 \\
\hline Width of nuclear island (m) & & & 26.67 \\
\hline Height of nuclear island (m) & & & 22.1 \\
\hline Radius of shield building (m) & & & 19.8 \\
\hline Radius of containment vessel (m) & & & 0.92 \\
\hline Wall thickness (m) & & & 39.42 \\
\hline Thickness of containment vessel (m) & & & \\
\hline Height of auxiliary building (m) & & & \\
\hline
\end{tabular}




\section{Results and discussion}

\subsection{Modal analysis}

The results obtained from the modal analysis, namely the first natural frequencies and the corresponding periods of the nuclear island building, are given in Table 2. The first two vibration modes of the building are depicted in Fig. 4, as an example. The first two natural frequencies and the periods of the present work are closed to the values obtained by Chen et al. in Ref. [8] for the case of the non-isolated system. It should be noted that the turbine building, the diesel generator building, the radwaste building in the present work are model as solids, and this can be explained by the difference between the results of the modal analysis obtained herein with that of Ref. [8]

Table 2. The first six natural frequencies and periods.

\begin{tabular}{|c|c|c|}
\hline Mode & Frequency (Hz) & Period (s) \\
\hline 1 & 3.6219 & 0.2761 \\
\hline 2 & 3.6294 & 0.2755 \\
\hline 3 & 3.6322 & 0.2753 \\
\hline 4 & 3.6781 & 0.2719 \\
\hline 5 & 3.7547 & 0.2663 \\
\hline 6 & 3.7553 & 0.26629 \\
\hline
\end{tabular}
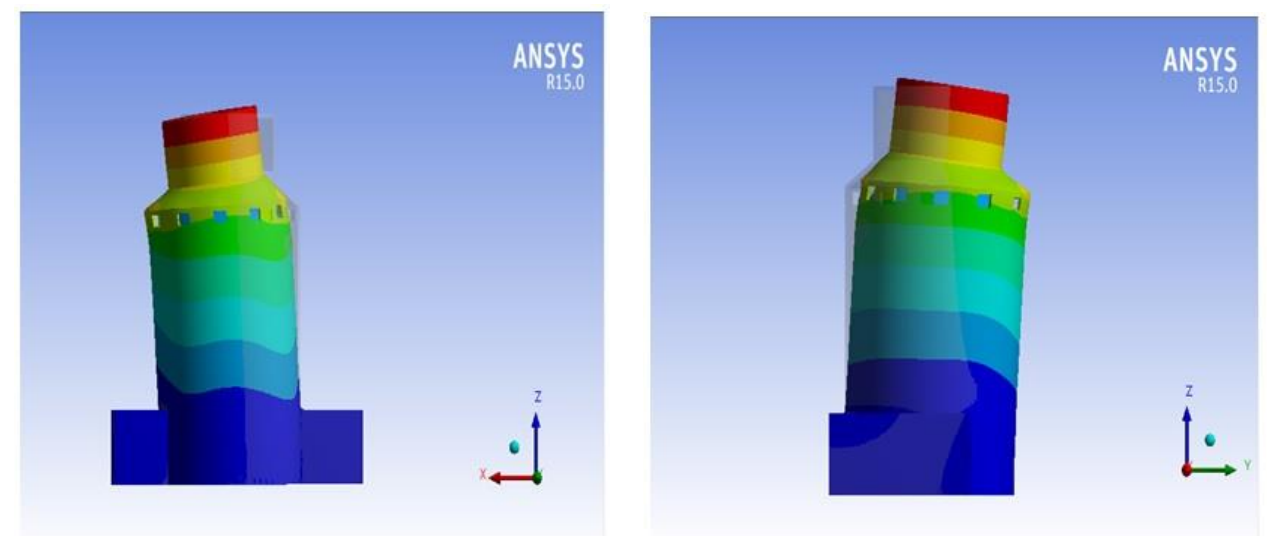

Fig. 4. The first two vibration modes of the nuclear island building 


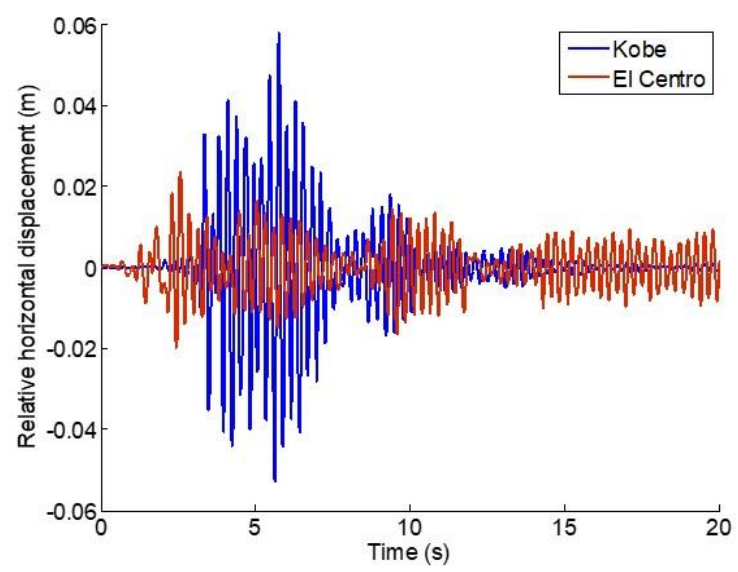

a) Displacement time history

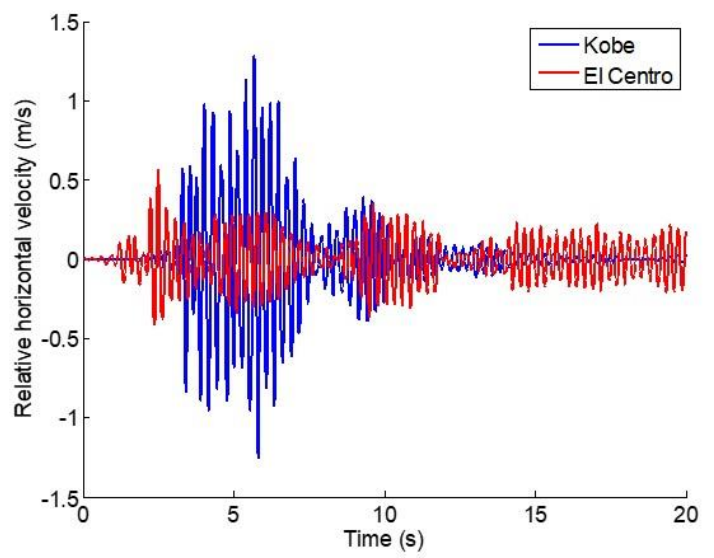

b) Velocity time history

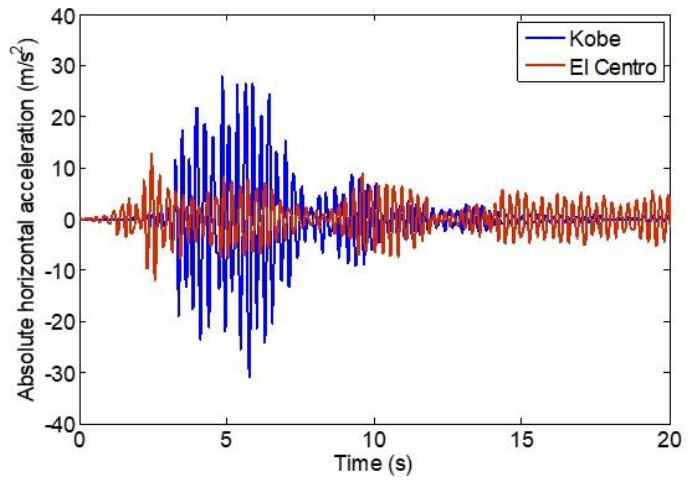

c) Acceleration time history

Fig. 5. Time history of the responses at responses at the top point. 


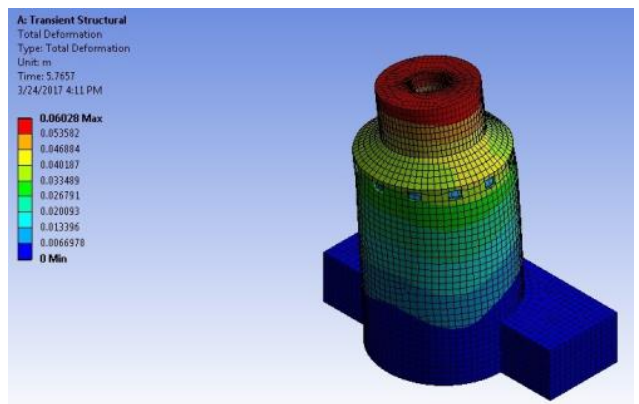

a) Kobe earthquake $(\mathrm{t}=5.7657 \mathrm{~s})$

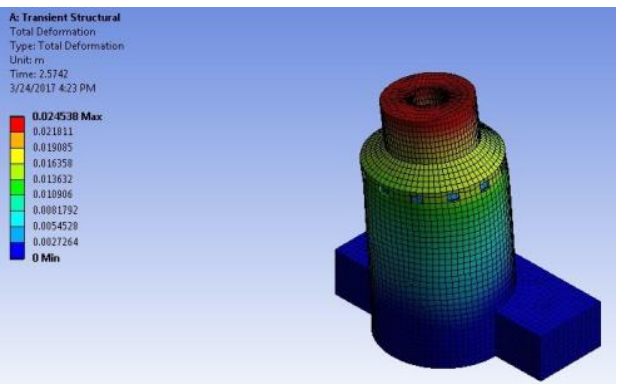

b) El Centro earthquake $(\mathrm{t}=2.5742 \mathrm{~s})$

Fig. 6. Deformed configuration of the nuclear island under different earthquake loadings corresponding to the maximum displacement

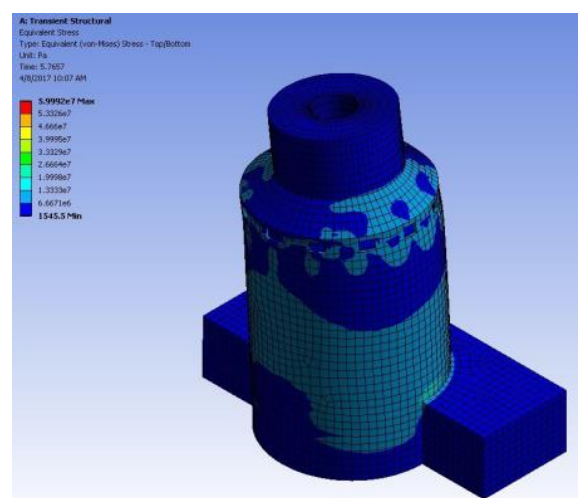

a) Kobe earthquake $(\mathrm{t}=5.7657 \mathrm{~s})$

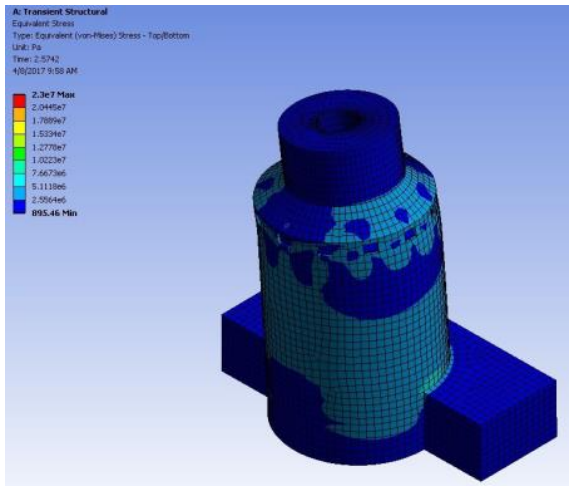

b) El Centro earthquake ( $\mathrm{t}=2.5742 \mathrm{~s})$

Fig. 7. Equivalent von Mises stress distribution of the nuclear island under different earthquake loadings at the time of the maximum displacement

Table 3. The maximum and minimum dynamic response at the top point

\begin{tabular}{|c|c|c|c|c|}
\hline \multirow{2}{*}{ Response } & \multicolumn{2}{|c|}{ Kobe Earthquake } & \multicolumn{2}{c|}{ El Centro Earthquake } \\
\cline { 2 - 5 } & Maximum & Minimum & Maximum & Minimum \\
\hline Displacement (m) & $5.7833 \times 10^{-2}$ & $-5.2869 \times 10^{-2}$ & $2.3512 \times 10^{-2}$ & $-1.984710^{-2}$ \\
\hline Velocity (m/s) & 1.2792 & -1.2530 & 0.56181 & -0.41577 \\
\hline Acceleration (m/ s $\left.{ }^{2}\right)$ & 27.9940 & -30.9320 & 12.659 & -11.999 \\
\hline
\end{tabular}

\subsection{Dynamic response}

Fig. 5a show the relative displacement response at the top point of the nuclear island building under the safe shutdown of the Kobe and El Centro earthquakes. The displacement response of the building is in accordance with the ATHs of the two earthquakes depicted in Fig. 1. As seen from the figure, the displacement response at the top point of the structure under the Kobe earthquake is much higher than that of the building under the El Centro earthquake. The response due to the Kobe earthquake is mainly contributed in the first 12 seconds, and it decays rapidly after this period. The displacement response under the El 
Centro earthquake is, however still relative large after the $12^{\text {th }}$ second, and even until the $20^{\text {th }}$ second, as seen from the figure. Similar remarks can be drawn for the response of the relative velocity and absolute acceleration at the top point as depicted in Fig. 5b and Fig. $5 \mathrm{c}$, respectively. Both the velocity and acceleration at the point decay of the building in the Kobe earthquake decay rapidly after the $12^{\text {th }}$ second, but they are still relative large until the $20^{\text {th }}$ second when the building is subjected to the El Centro earthquake.

In order to examine the dynamic response of the nuclear island building under the Kobe and El Centro earthquakes in more detail, Figs. 6 and 7 illustrate the deformed configurations and the equivalent von Mises stresses of the building at the times they reach the maximum displacements. The equilibrium von Mises in the figures is defined as follows

$$
\sigma_{\mathrm{vM}}=\sqrt{\frac{1}{2}\left[\left(\sigma_{1}-\sigma_{2}\right)^{2}+\left(\sigma_{2}-\sigma_{3}\right)^{2}+\left(\sigma_{3}-\sigma_{1}\right)^{2}\right]}
$$

with $\sigma_{1}, \sigma_{2}$ and $\sigma_{3}$ are, respectively, the first, the second and the third principle stresses. Figure 6 show the horizontal displacements at the top of the shield building are the largest, and they are smaller in the lower parts of the building. The situation is different for the von Mises stress, and the stress tends to be larger in the areas of the shield building which are near the lower part of the nuclear island. It should be noted that the von Mises stress at some areas of the building under the Kobe earthquake is of the order of $10^{7} \mathrm{~Pa}$, which is quite large and it may exceed the yield stress. In this case, a nonlinear analysis is necessary to perform, but it is beyond the scope of this paper. The large dynamic response of the nuclear island building under the Kobe earthquake compares to the El Centro earthquake can be observed again from the figures. Table 3 summarizes the maximum and minimum values of the displacement, velocity and acceleration response of the building in the two earthquakes. One can see from the Table that the critical response values obtained in the Kobe earthquake are more than two times higher than that obtained in the El Centro earthquake. From a safety point of view, the nuclear island building is more dangerous in the Japanese Kobe earthquake than it is in the American El Centro earthquake.

\section{Conclusions}

The dynamic response of the AP1000 nuclear island building under safe shutdown earthquakes has been investigated in the present paper. With the help of the software ANSYS, a 3D finite element model for the building has been created, and its dynamic response was computed. The dynamic characteristics, including the relative displacements, velocities and the absolute accelerations of the building, assuming to be built on a hard rock base, have been obtained by using the ATHs of the Kobe 1995 and El Centro 1944 earthquakes. The deformed configurations and the von Mises distribution of the building under the earthquakes have also been computed. The obtained numerical results have shown that the nuclear island building displaced larger under the Kobe earthquake than it does under the El Centro earthquake. It has also revealed that the safety of the building under the Japanese earthquake is much more concerned than in the El Centro earthquake. The von Mises stress at some parts of the building when it is subjected to the Kobe earthquake may exceed the yield stress, and more works are necessary to carried out to take the material nonlinearity into consideration in studying the dynamic behavior of the nuclear island building under seismic loading.

The support from Vietnam Academy of Science and Technology (Grant No. VAST01.06/16-17) to Dr. Nguyen Dinh Kien is gratefully acknowledged. 


\section{References}

1. R.D. Campbell, G.S. Hardy, M.K. Ravindra, J.J. Johnson, A.J. Hoy, Nucl. Eng. Des, 182, 17 (1998)

2. L. Tunon-Sanjur, R.S. Orr, S. Tinic, D.P. Ruiz, Nucl. Eng. Des. 237, 1474 (2007)

3. M. Manjuprasad, S. Gopalakrishnan, T.V.S.R. Appa Rao, Eng. Struct. 23, 397 (2001)

4. N. Nakamura, Nucl. Eng. Des. 238, 1845 (2008)

5. N. Nakamura, S. Akita, T. Suzuki, M. Koba, S. Nakamura, T. Nakano, Nucl. Eng. Des. 240, 166 (2010)

6. F. Perotti, M. Domaneschi, S. De Grandis, Nucl. Eng. Des. 262, 189 (2013)

7. C. Zhao, J. Chen, Nucl. Eng. Des. 265, 484 (2013)

8. I. Chen, C. Zhao, Q. Xu, and C. Yuan, Nucl. Eng. Des. 278, 117 (2014)

9. C.-H. Zhai, Z. Zheng, S. Li, L.-L. Xie, Soil Dyn. Earthq. Eng. 74, 46 (2015)

10. I . Politopouos, I. Sergis, F. Wang, Soil Dyn. Earthq. Eng. 78, 213 (2015)

11. K.C. Senera, A.H. Varma, P.N. Bootha, R. Fujimoto, Nucl. Eng. Des. 295, 804 (2015)

12. Q. Xu, J. Chen, C. Zhang, J. Li, C. Zhao, Nucl. Eng. Tech. 48, 246 (2016)

13. Lee, D.-S., Liu, M.-L., Hung, T.-C., Tsai, C.-H., Chen, Y.-T., Appl. Therm. Eng. 50, 207 (2013).

14. A.K. Chopra, Dynamics of structures, theory and applications to earthquake engineering ( $4^{\text {th }}$ edition, Prentice Hall, Boston, 2014).

15. R.D. Cook, D.S. Malkus, M.E. Plesha, Concepts and applications of finite element analysis ( $3^{\text {rd }}$ edition, John Wiley \& Sons, New York, 1989).

16. T.J. Katona, Seismic safety analysis and upgrading of operating nuclear power plant, Intech, http://dx.doi.org/10.5772/51368 (2012).

17. Inc. A., ANSYS Release 15.0 (Canonsburg, PA, USA, 2013). 